\title{
How long does the modality effect persist?
}

\author{
RANDALL W. ENGLE and JAMES S. ROBERTS \\ University of South Carolina, Columbia, South Carolina 29208
}

\begin{abstract}
Two experiments were conducted to study the modality effect with delayed free recall. The first experiment demonstrated that both auditory and vocalized-visual presentations were superior to silent visual presentation even when recall was delayed by $15 \mathrm{sec}$. The second experiment demonstrated that a slight modality effect was obtained even after a recall delay of 60 sec if the filler task was not auditory in nature. These studies suggest either that echoic memory persists longer than was previously believed or that the modality effect and suffix effect are mediated by different mechanisms.
\end{abstract}

The superior recall of auditorily presented material over visually presented material in short-term memory tasks has long been considered one of the primary sources of converging evidence for the existence of an auditory sensory store (Crowder \& Morton, 1969). Furthermore, it has been argued that this auditory or echoic trace persists about $1-2 \mathrm{sec}$, which would be long enough to aid performance on immediate memory tests (Crowder, 1972). This brief estimate of the duration of echoic memory was obtained using the suffix procedure, in which a nonrecalled redundant speech sound is appended to a list of items presented for serial recall.

However, studies on the modality effect, particularly those using immediate free recall, have begun to suggest much longer estimates for echoic persistence. For example, Craik (Note 1) used a free recall task in which subjects received lists presented either visually or auditorily. One group recalled the items immediately after presentation, a second group had $5 \mathrm{sec}$ of silent rehearsal prior to recall, and a third group silently rehearsed for $15 \mathrm{sec}$ prior to recall. Craik observed that the auditory superiority for the recency items was just as large when recall was delayed by $15 \mathrm{sec}$ as it was for the group given immediate recall. While this could suggest that the echoic trace persists for $15 \mathrm{sec}$ or longer, it also is possible that the items available in echoic memory immediately after presentation are simply transferred to short-term memory during the silent rehearsal period and the high level of performance for recency items given auditory presentation actually reflects recall from the nonsensory short-term memory.

Also relevant to this issue of the duration of echoic memory is a study by Watkins, Watkins, Craik, and Mazuryk (1973). Their subjects received either auditorily or visually presented lists, followed by a $40-\mathrm{sec}$ interval during which subjects (1) recalled the lists for

This work was facilitated by Grant HD-11114 from the National Institute of Child Health and Human Development. Requests for reprints should be sent to Randall Engle, Psychology, University of South Carolina, Columbia, South Carolina 29208. the first $20 \mathrm{sec}$ and then performed an attentiondemanding pursuit task for $20 \mathrm{sec}$, (2) covertly rehearsed for $20 \mathrm{sec}$ and then recalled the items (a condition similar to Craik's, Note 1, study), or (3) performed the pursuit task for $20 \mathrm{sec}$ and then recalled the items. The results demonstrated a significant superiority even after $20 \mathrm{sec}$ of the attention-demanding task. This would seem to negate any argument that the auditory items are recalled better after the delay because they are more likely to be rehearsed during the interval.

More recently, Broadbent, Vines, and Broadbent (1978) demonstrated not only auditory superiority after delayed recall but also that the modality of the interpolated task would interact with the modality of the list in a manner that might be expected if the modality effect reflects the existence of an auditory sensory memory. In this study, auditorily and visually presented lists were recalled either immediately or $16 \mathrm{sec}$ after presentation. The interpolated task consisted of the subject's copying down numbers that were presented either auditorily or visually. Broadbent et al. found that if the interpolated task was in the same mode as the list words, the recency component was reduced by equal amounts for auditory and visual presentations. For cross-modal interpolated task conditions, however, copying of visual numbers caused no decrement for auditorily presented lists, but copying of auditory numbers did cause a decrement for visually presented lists, thereby yielding an increased modality effect at the long delay. This might suggest that the auditory recency items were coded in a form not requiring attention for persistence-presumably, the preattentive echoic store.

Thus, there is considerable evidence that auditory presentation will continue to lead to enhanced recall of recency items even after delays as great as $30 \mathrm{sec}$. It has been characteristic of all of the above findings, however, that the modality effect after the delay was just as large, in fact larger in some cases, than immediately after presentation. If this delayed modality effect represents a true echoic sensory memory, then a gradual decline in auditory superiority should be observed, since 
logic dictates that the auditory sensory store resemble the visual store in losing information over time. One purpose of the research reported here was to extend the recall delays after presentation to see whether the modality effect begins to decrease with longer delays than have previously been used. Another purpose of this research was to see how similar in other respects the delayed modality effect is to that found after immediate free recall. For example, numerous studies have shown that vocalized-visual presentation will lead to the same pattern of enhanced recall as auditory presentation (Penney, 1975). Presumably, vocalizedvisual presentation results in an echoic trace from the subject's own voice that is identical to that following auditory presentation. If this argument is true and if the delayed modality effect is a result of a long-lasting auditory sensory store, then we should observe the same delayed modality effect with vocalized-visual presentation. On the other hand, if the delayed modality effect is not a result of an auditory sensory store, then we may observe vocalized-visual presentation to yield a pattern different from that produced by auditory presentation.

\section{EXPERIMENT 1}

\section{Method}

Subjects and Materials. The subjects were 60 undergraduate introductory psychology students who participated for extra credit. Twenty lists of 12 high-frequency words were presented either by slide projector or by tape recorder at a 1.2 -sec/word presentation rate.

Design and Procedure. The variables of primary concern in this experiment were modality of presentation and recall condition. Modality was a between-subjects variable and was (1) visual presentation with the subject remaining silent during presentation, (2) visual presentation with the subject reading the word aloud, or (3) auditory presentation via speakers. Recall condition was varied within subjects. In the no-delay condition, the subjects were shown (in all modality conditions) a question mark that signaled that free recall was to begin immediately. In the 15 -sec unfilled-delay condition, the subjects saw a blank slide after the presentation of the last item that indicated that they were free to do as they wished for $15 \mathrm{sec}$, after which a slide of a question mark was presented as the cue to begin free recall. In the 15-sec filled-delay condition, the subjects in all presentation conditions saw a slide of a three-digit number. They were to write this number down on their recall sheet and to begin to subtract from this number by threes in writing on their answer sheet as quickly as possible. At the end of the $15-\mathrm{sec}$ period, all subjects saw a question mark, which was the cue to begin free recall immediately. The instructions emphasized that it was very important to get as many correct subtractions as possible. A fourth recall condition was identical to the 15 -sec filled-delay condition, except, in addition to the $15 \mathrm{sec}$ of number subtraction, the subject continued to subtract for the full $60 \mathrm{sec}$ that was allocated for recall in the other conditions. After the $75 \mathrm{sec}$ of subtracting, the subject was simply presented the next list. After the last list, subjects were given 2 min to relax and were then given a surprise final free recall test. They were told to take about 5 min and try to recall as many words as they could from all the lists, including those they did not attempt to recall earlier. This recall, like that for each of the lists, was written on a separate sheet of paper.

\section{Results}

Immediate recall. The results of the free recall test are shown in Figure 1, in which we can see that the typical effects of modality are present with each of the recall conditions. First of all, it should be observed that the auditory and the vocalized-visual conditions are virtually coincident across the three recall conditions, showing that vocalization of visual input is, under the present conditions, equivalent to auditory input in its effect on recall. In addition, the two standard modality effects are both present in these data. That is, there is a slight superiority of the visual over the auditory and the vocalized-visual conditions for the first two serial positions; however, the last four serial positions show a strong advantage for the auditory and vocalized-visual presentations. Again, looking across the recall conditions, we can see that there is a slight decrease in the level of recall, particularly for the recency positions, when recall is delayed by $15 \mathrm{sec}$. In fact, this decrease appears to be greater for the visual condition, giving rise to a larger modality effect for the delayed recall conditions. It does not make much difference, however, whether the $15 \mathrm{sec}$ is filled with a rehearsal-preventative task or is unfilled. The magnitude of the modality difference is about the same for the two conditions. These observations were supported by significant main effects of delay $[F(2,96)=34.3, p<.001]$ and

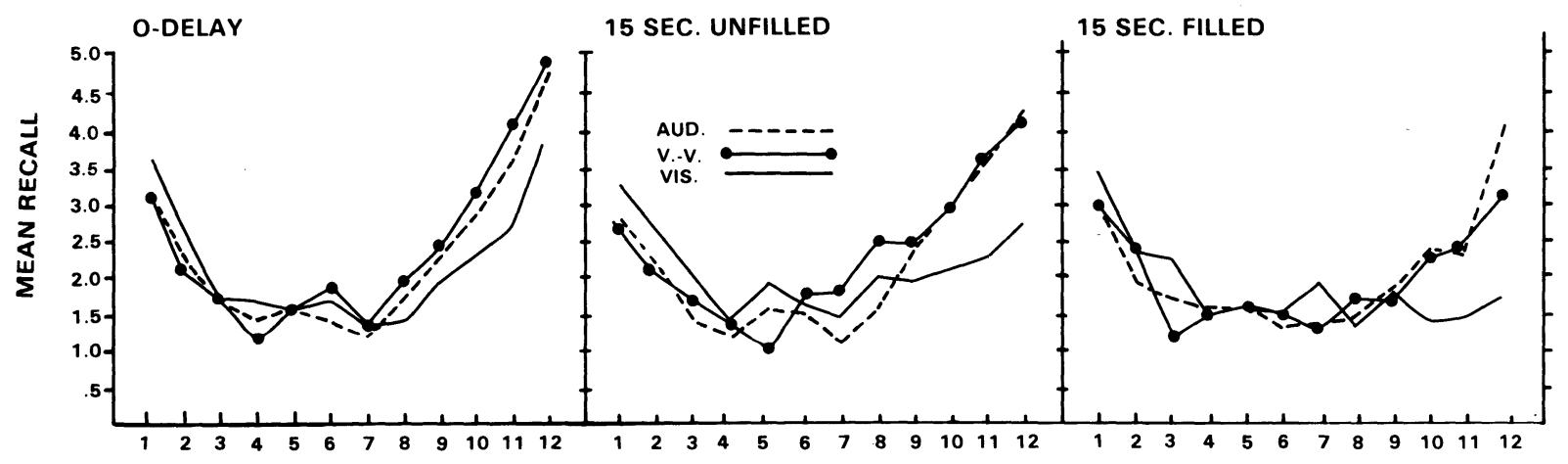

SERIAL POSITION

Figure 1. Mean number of words recalled as a function of serial position. 
serial position $[F(11,528)=72.7, p<.001]$ and significant interactions of Modality by Serial Position $[\mathrm{F}(22,528)=6.3, \mathrm{p}<.01]$ and Delay by Serial Position $[\mathrm{F}(22,1056)=5.7, \mathrm{p}<.01]$.

Final free recall. The final free recall of all presented lists showed no interesting results. Aside from the standard finding of negative recency for the last few positions, there were no significant main effects or interactions.

\section{Discussion}

The results of this experiment demonstrated that the modality effect found with recall delayed by $15 \mathrm{sec}$ was similar for vocalized-visual and for true auditory presentation, in the same way it was for the conditions given immediate recall after presentation. This suggests that the same underlying mechanism may be responsible for the delayed and immediate modality effect. If echoic sensory memory is that mechanism, then its duration is certainly longer than the $1-2 \mathrm{sec}$ proposed by Crowder (1972).

In the following experiment, recall was delayed for up to $60 \mathrm{sec}$ to see whether the modality effect starts to diminish in magnitude with delays longer than those used previously. If it does not diminish after rather long recall delays, then it is not likely that a sensory trace is responsible for the auditory superiority, since it seems unreasonable that we would have available the sensory trace at full strength for nonmasked auditory stimuli presented $60 \mathrm{sec}$ previously. It seems appropriate here to try to distinguish between sensory memories and perceptual memories. One alternative to the view that modality effects are a result of echoic traces is that there is an additional form of coding that might be analogous to visual imagery. Visual images are probably perceptual in nature, but they do not show the quick loss over time that has been shown in studies of visual sensory memory. If no decline in the modality effect is demonstrated in the delayed free recall paradigm, then this would suggest that the modaltiy effect may be more a result of auditory perceptual codes that are not truly sensory in the way that echoic traces are assumed to be.

It is possible that previous studies have not shown a decline in the modality effect with delayed recall because the intervening task was not demanding enough. Broadbent et al. (1978) presented seven double-digit numbers that were to be copied down as they were presented. Watkins and Watkins (1980) visually presented six long words that were to be copied down before recall began. Neither one of these tasks requires that a major transformation be performed on the incoming stimuli, and thus they probably do not demand much attention. In the next experiment, we use a number subtraction task that has been shown to be relatively attention demanding.

\section{EXPERIMENT 2}

\section{Method}

Subjects and Materials. The subjects were 108 students of introductory psychology classes who served for extra credit in their course. Twenty-four lists, composed of 12 familiar words each, were used as stimuli. Each word, 24 different three-digit numbers, and 24 copies of a question mark were photographed for slide presentation. All stimuli were presented by Kodak projector at a rate of $1.2 \mathrm{sec} /$ word.

Design and Procedure. The variables of consequence in this study were modality of presentation, recall delay, and nature of the task that filled the recall delay. While all the subjects received visual presentation of the word lists, half of the subjects viewed them silently, and we will refer to this as the visual condition. The other half of the subjects read the words aloud at input, and, for the sake of continuity and in light of the previous experiment, we will refer to this as the auditory condition. Recall of the list items was delayed by 15,30 , or $60 \mathrm{sec}$. The order of delay was randomized so that a subject was not aware of the delay being used at a given time until the recall cue was presented. Three different orderings of the various recall delays were used across subjects. Nature of the filler task was a betweensubjects variable, with the delay filled by no task, a visual task, or an auditory task. The subjects in the no-task condition saw a three-digit number after the last list item, but they were told to ignore it and they were told that they could relax and do as they wished during the recall delay. Subjects in the visual filler condition saw a three-digit number after the last list item and they were instructed to copy the number on their answer sheet and to subtract from the number by threes as rapidly and as accurately as possible. Those subjects who were in the auditory filler condition also saw a three-digit number following the last list item, but they read it aloud and proceeded to subtract from the number by threes orally, with the same instructions to be rapid and accurate that were given in the visual filler condition. Each 12-word list was divided into three 4-word groups, and the order of these groups was counterbalanced over subjects. After the delay period concluded, a question mark was projected onto the screen and the subjects were given $60 \mathrm{sec}$ to write down their responses on an answer sheet in any order they wished.

\section{Results}

The mean number of words recalled as a function of serial position, input modality, length of recall delay, and nature of filler task is shown in Figure 2. We can see from Figure 2 that, for the no-filler condition, the auditory superiority is present at all three delay conditions and is just about as large after a 60 -sec delay as after a 15 -sec delay. When the filler task was visual in nature, the modality effect was as large after the 15-sec delay as in the no-filler condition. However, after a 30 -sec delay, the modality effect had declined in magnitude

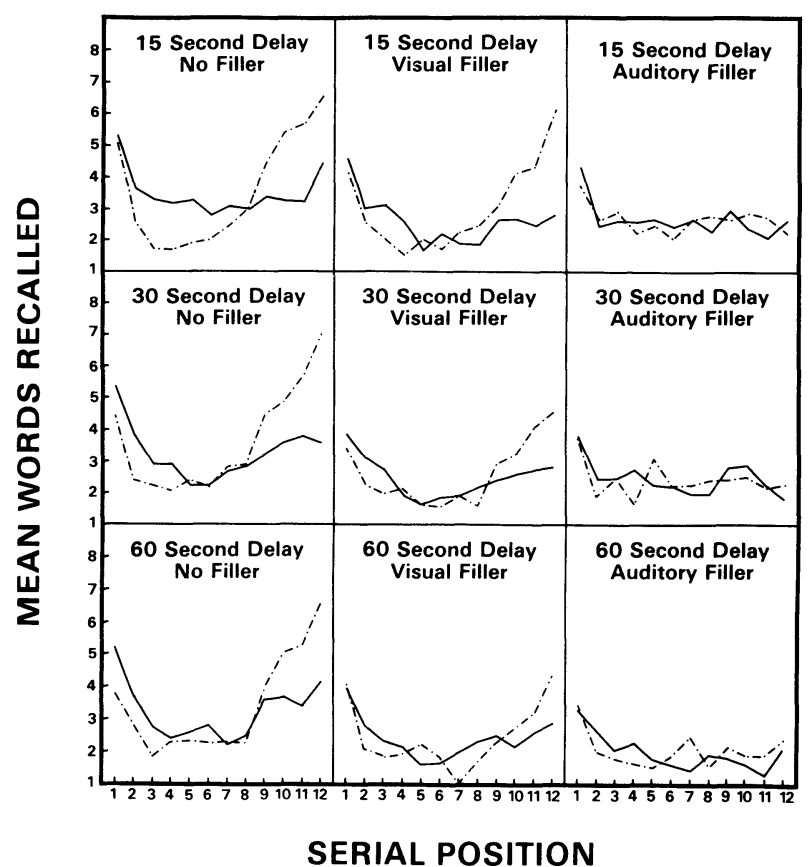

- Visual Presentation Auditory Presentation

Figure 2. Mean number of words recalled as a function of serial position. 
Table 1

Mean Number of Words Recalled for the Last Four Positions

\begin{tabular}{llll}
\hline \multicolumn{2}{c}{ Visual Input } & \multicolumn{2}{c}{ Auditory Input } \\
\hline VN & 3.63 & AN & 5.47 \\
VV & 2.65 & AV & 3.81 \\
VA & 2.24 & AA & 2.36 \\
\hline
\end{tabular}

compared with the no-filler condition. And by $60 \mathrm{sec}$ after the presentation of the last item, the auditory superiority was rather small, although still significant.

Now turning to the auditory filler task, apparently $15 \mathrm{sec}$ of the auditory filler task was enough to eliminate the auditory superiority, since even the shortest recall delay resulted in no difference between auditory and visual presentation conditions. Although overall performance became worse with longer delays, the auditory and visual input conditions never differed when the filler task was auditory in nature.

These conclusions were supported by the results of the analysis of variance. There were significant main effects of serial position $[F(11,594)=64.3, p<.001]$, mode of filler task $[F(2,54)=29.5, p<.001]$, and length of recall delay $[\mathrm{F}(2,108)=48.6, \mathrm{p}<.001]$. In addition, there were significant interactions of Mode of Presentation by Serial Position $[F(11,594)=19.3$, $\mathrm{p}<.001]$, Mode of Filler by Serial Position $[F(22,594)=11.5, p<.001]$, and Mode of Presentation by Mode of Filler by Serial Position $[\mathrm{F}(22,594)=4.3$, $\mathrm{p}<.001]$.

Paired comparisons of performance from only the recency positions in Figure 2 were performed using Scheffé tests at the .05 level. These means are shown in Table 1. When the input mode was visual, there was no difference between the effects of a visual filler task and an auditory filler task. When the input mode was auditory, however, the auditory filler had much more of a detrimental effect than did the visual filler and, in fact, eliminated any auditory advantage over the visual condition.

\section{GENERAL DISCUSSION}

The results of these two studies show quite clearly that the modality effect, the superiority of auditory over visual presentation, occurs at recall delays much longer in duration than would be expected from estimates of echoic memory derived from the suffix procedure. While the auditory superiority was found even after a delay of $60 \mathrm{sec}$, it did diminish over time when rehearsal was prevented by a task shown to be attention demanding. This appears to be a necessary but not sufficient condition for any notion that modality effects are a result of sensory traces.

We can only make a weak inference that the storage of the recency items following auditory input was in some kind of auditory sensory code. The auditory filler task did interfere with auditory input more than did the visual filler task. But interpretation of the results of a retroactive interference design is difficult and depends on the two conditions, auditory and visual input in this case, being equal in degree of original learning. The number of items recalled in immediate free recall typically is not different for auditory and visual input, but, of course, there is an interaction of modality and serial position such that more visual primacy items are recalled but more auditory recency items are recalled. Since our interest here is primarily in the modality difference for the recency items, it is probably not safe to assume "equal degree of original learning." Thus, we cannot give an unequivocal answer to the question of whether the modality effect, after either immediate or delayed recall, is a result of lingering echoic traces of the recency items that make these items more available for recall. But the results of these studies, along with the results of Watkins and Watkins (1980) and others, certainly do suggest either that echoic memory persists for up to $60 \mathrm{sec}$ or that the modality effect and the suffix effect are mediated by different mechanisms.

It is becoming increasingly difficult to draw the same conclusions from the two most common procedures used to make inferences about echoic memory, that is, the suffix procedure and comparison of auditory and visual presentation. Perhaps the best example of this is the rather dissociative nature of the recent findings from our laboratory. The current studies, using the modality effect to make inferences about echoic memory, suggest an echoic memory that endures for up to $60 \mathrm{sec}$. Further, if the extent of the auditory superiority over the final portion of the list is any index of the capacity of echoic memory, it appears that up to three to five recency items benefit from auditory presentation.

Recently, however, our laboratory reported another study (Balota \& Engle, 1981) that supported the notion that echoic memory is of limited capacity. This study used the suffix procedure and suggested that, while the suffix effect might extend over several of the final serial positions, only the decrement in performance for the last item is a result of the suffix masking the echoic trace of the item. The decrement in performance for the penultimate positions appears to be a result of a strategic attentional mechanism that is not sensory in nature. In other words, that study suggested that echoic memory retains only the last item in the list, and not the three to five items suggested by the modality effect.

It is possible that both views are correct, that echoic memory is limited to the single last item heard by the subject and that this trace persists for up to $60 \mathrm{sec}$. However, there obviously needs to be more work done to try to integrate the diverging conclusions of these two procedures that at one time were assumed to reflect the same psychological process.

\section{REFERENCE NOTE}

1. Craik, F. I. M. Modality differences in short-term free recall. Paper presented to the annual meeting of the A.A.A.S., Boston, December 1969.

\section{REFERENCES}

Balota, D. A., \& Engle, R. W. Structural and strategic factors in the stimulus suffix effect. Journal of Verbal Learning and Verbal Behavior, 1981, 20, 346-357.

Broadbent, D., Vines, R., \& Broadbent, M. Recency effects in memory as a function of modality of intervening events. Psychological Research, 1978, 40, 5-13.

Crowder, R. G. Visual and auditory memory. In J. F. Kavanaugh \& I. G. Mattingly (Eds.), Language by ear and by eye: The relationships between speech and reading. Cambridge, Mass: M.I.T. Press, 1972.

Crowder, R. G., \& Morton, J. Precategorical acoustic storage (PAS). Perception \& Psychophysics, 1969, 5, 365-373.

Penney, C. G. The modality effect in short-term verbal memory. Psychological Bulletin, 1975, 82, 68-84.

Watkins, M. J., Watkins, O. C., Craik, F. I. M., \& Mazuryk, G. Effect of nonverbal distraction on short-term storage. Journal of Experimental Psychology, 1973, 101, 296-300.

Watkins, O. C., \& Watkins, M. J. The modality effect and echoic persistence. Journal of Experimental Psychology: General, 1980, 109, 251-278.

(Received for publication March 22, 1982.) 